\title{
Análise de mudanças na poluição atmosférica e sua relação com o isolamento social em função da pandemia da COVID-19 no Nordeste Brasileiro
}

\author{
Analysis of changes in air pollution and its relationship with social \\ isolation due to the COVID-19 pandemic in Brazilian Northeast
}

\author{
Laizy de Santana Azevedo ${ }^{1}$ \\ Ana Lúcia Bezerra Candeias ${ }^{2}$ \\ João Rodrigues Tavares Júnior ${ }^{3}$
}

Palavras-chave:

Imagens de Satélite

Coronavírus

Dióxido de Nitrogênio

Profundidade Óptica de

Aerossol

\begin{abstract}
Resumo
Em março do ano 2020, a Organização Mundial de Saúde (OMS) declarou a Covid-19 como uma pandemia. Neste contexto, acreditou-se então, que as medidas de isolamento social adotadas para retardar a disseminação desse vírus poderiam ter reduzido o nível de poluentes atmosféricos, como o dióxido de nitrogênio $\left(\mathrm{NO}_{2}\right)$ e a Profundidade Óptica de Aerossol (AOD). Diante disso, a presente pesquisa identificou alterações na poluição atmosférica no Nordeste do Brasil através de imagens de satélite MODIS Terra / Aqua AOD e Sentinel 5P-TROPOMI para investigar alterações de AOD e $\mathrm{NO}_{2}$, respectivamente, durante o primeiro semestre de $2020 \mathrm{em}$ relação ao mesmo período em 2019. O resultado revelou que o $\mathrm{NO}_{2} \mathrm{em}$ quase todo o Território, foi reduzido no segundo bimestre de $2020(-4,49 \%)$, o que corresponde ao período de início do bloqueio social. Já o terceiro bimestre apresentou aumento de 2,26\%. Em relação ao AOD, apesar das desacelerações na interação social, não houve queda significativa. Também foi realizada uma verificação de poluentes em algumas áreas estratégicas, sendo elas: áreas urbanas, industriais e entorno de reservatórios de água e os resultados revelaram semelhanças entre as análises realizadas para o Nordeste como um todo e para estas áreas.
\end{abstract}

\section{Keywords:}

Satellite Images.

Coronavírus.

Nitrogen Dioxide.

Aerosol Optical Depth.

\begin{abstract}
In March 2020, the World Health Organization declared the Covid-19 a pandemic. It was considered that social isolation measures adopted to slow the spread of the virus, could have reduced the level of pollutants such as nitrogen dioxide (NO2) and AOD (Aerosol Optical Depth). Therefore, this research identified changes in atmospheric air pollution in Northeast Brazil through MODIS Terra / Aqua AOD and Sentinel 5P-TROPOMI images to investigate changes in $\mathrm{AOD}$ and $\mathrm{NO} 2$, respectively, during the first half of 2020 compared to the same period in 2019. The result revealed that NO2 in almost the entire Territory decreased in the second two months of $2020(-4,49 \%)$, which corresponds to the beginning of social blocks. The third bimester showed an increase of $2.26 \%$. Regarding AOD, despite the slowdowns in social interaction, there was no significant drop. Pollutant levels were also checked in urban, industrial areas and around water reservoirs and the results showed similarity between the analyzes carried out for the Northeast and these areas.
\end{abstract}




\section{INTRODUÇÃO}

No final do ano de 2019 um evento epidêmico começou na China. O surto de um vírus, chamado de novo coronavírus (SARS-CoV-2), foi declarado como pandemia pela Organização Mundial de Saúde em março de 2020 (OMS, 2020). Neste contexto, medidas de isolamento social foram implementadas como forma de redução do contágio desse vírus. Essas medidas provocaram reduções de aerossóis e poluentes atmosféricos em várias partes do mundo.

Estudos realizados pela NASA (2020) mostraram que a poluição atmosférica diminuiu, principalmente na China, em decorrência das medidas de distanciamento social estabelecidas para retardar a disseminação desse vírus. Autores como Ranjan et al., (2020) observaram que os bloqueios sociais causaram reduções na poluição em regiões urbanas da Índia, porém, nas áreas de mineração a poluição aumentou. No Brasil, pesquisadores também realizaram estudos semelhantes concentrando-se na região Sudeste do país (DANTAS et al., 2020; BRANDÃO, 2020)

Entender como a poluição do ar é afetada por interrupções extremas nas relações sociais devido a Covid-19 pode fornecer subsídios importantes em relação ao controle das emissões de poluentes atmosféricos. De acordo com a Organização das Nações Unidas - ONU (2019), a população mundial deve aumentar em cerca de 2 bilhões de pessoas nos próximos 30 anos. Esse crescimento acelerado traz como uma das principais consequências o aumento da poluição do ar (KAPLAN E AVDAN, 2020). O crescimento populacional aliado a exposição a poluentes atmosféricos geram impactos negativos na qualidade do meio ambiente e na saúde humana (HOU et al., 2019). Sendo assim, o estudo de poluentes atmosféricos é fundamental, pois, eles trazem consequências negativas para a população.

O uso de imagens de satélite para detectar mudanças na qualidade do ar vem sendo empregado para observar diversos poluentes presentes na estratosfera e troposfera. Dentre eles, podemos destacar o dióxido de Nitrogênio $\left(\mathrm{NO}_{2}\right)$ e os aerossóis. $\mathrm{O} \mathrm{NO}_{2}$ é um dos principais componentes da poluição do ar urbana sendo gerado principalmente por ações antrópicas (BECHLE et al., 2013). Ele é um gás poluente, com cheiro forte e coloração castanha que fica concentrado próximo às fontes poluidoras, dando um tom escuro ao ambiente com maiores taxas de concentração. Altas concentrações desse gás podem ocasionar problemas respiratórios e pulmonares e levar a formação de smog fotoquímico e de chuva ácida.

O AOD (Profundidade Óptica de Aerossol) é um parâmetro físico adimensional que indica o quanto o feixe de radiação é atenuado pelos aerossóis à medida que se propaga em uma determinada camada da atmosfera que contenha aerossóis. Eles podem ser definidos como partículas sólidas ou líquidas em suspensão na atmosfera provenientes tanto de fontes naturais quanto antropogênicas, dentre elas: poeira mineral do solo, fuligem e gases de erupções vulcânicas, material biogênico de floresta, queima de biomassa, dentre outras (PRADO e COELHO, 2017). Eles afetam a estabilidade atmosférica, a precipitação, o ciclo hidrológico, a cobertura vegetal e seu crescimento, além de aumentar os problemas respiratórios em humanos (LAL et al., 2020)

Convencionalmente, a qualidade do ar é monitorada a partir de estações terrestres. Essas medições no solo, apesar de serem capazes de indicar precisamente o nível de concentração de poluentes atmosféricos, apresentam um monitoramento limitado pelo alto custo e escassa cobertura espacial. Neste sentido, a detecção remota apresenta vantagens, fornecendo informações sobre a poluição do ar em áreas extensas de maneira rápida e eficiente (SOUZA et al., 2017).

Diante disto, esta pesquisa verificou mudanças nos níveis de poluentes atmosféricos na região Nordeste do Brasil como um todo, analisando também, algumas áreas consideradas fontes potenciais de emissão de poluentes e áreas que sofrem impactos negativos com a poluição do ar. Além disso, também buscou-se estudar a relação entre poluentes do ar e o isolamento social ocasionado em função da pandemia da Covid-19. O estudo foi realizado por meio do processamento de imagens de satélite do TROPOMI Sentinel 5P e MODIS AOD ao longo do primeiro semestre de 2019 e 2020. O estudo foi conduzido utilizandose a plataforma de processamento de dados do Google Earth Engine (GEE), que disponibiliza as imagens permitindo seu processamento em nuvem.

$\mathrm{O}$ produto $\mathrm{NO}_{2}$ do Sentinel - 5P (Precursor) faz parte do programa de monitoramento global Copernicus e é dedicado ao monitoramento da atmosfera (ESA, 2020). A missão consiste em um satélite com o instrumento Tropospheric Monitoring Instrument (TROPOMI) cujo objetivo principal é realizar medições atmosféricas com alta resolução espaço-temporal a serem usadas em estudos da qualidade do ar, radiação de ozônio e ultravioleta e monitoramento e previsão do clima. O satélite foi lançado em outubro de 2017 na Rússia e tem resolução de 0,01 graus (ESA, 
2020).

Já o produto AOD MODIS monitora globalmente a espessura óptica do aerossol sobre os oceanos e continentes (NASA, 2020). A profundidade óptica do aerossol (AOD) é uma medida do conteúdo do aerossol atmosférico colunar. O MODIS (Moderate Resolution Imaging Spectroradiometer) é um instrumento a bordo dos satélites Terra e Aqua. Após anos em operação, um novo algoritmo Multiangle Implementation of Atmospheric Correction (MAIAC) foi desenvolvido para o MODIS fornecendo dados diários AOD com resolução espacial de $1 \mathrm{~km}$ (CHUDNOVSK et al., 2014).

\section{MATERIAIS E MÉTODOS}

\section{Área de estudo}

A área de estudo compreende ao Nordeste do Brasil que é uma das cinco regiões do país (Figura 1). Essa região foi escolhida devido a carência de estudos relacionadas a poluição atmosférica nesta área. Segundo o Instituto de Energia e Meio Ambiente (IEMA- 2018), apenas nove dos vinte e sete estados brasileiros monitoram a qualidade do ar e a grande maioria deles concentram-se nas regiões sul e sudeste do país.

Como essa região é bastante extensa em dimensão territorial, além de uma análise abrangente em sua totalidade, também foram escolhidas algumas regiões estratégicas chamadas de "áreas testes" para verificar alterações na poluição atmosférica de forma mais detalhada durante a pandemia.

Foram escolhidas áreas consideradas fontes potenciais de emissão de poluentes e áreas que sofrem impactos negativos com a poluição do ar. As regiões escolhidas compreendem a áreas urbanas, áreas industriais e entorno de reservatórios de água. As áreas urbanas correspondem as cidades de Recife e Caruaru$\mathrm{PE}$, as áreas de atividades industriais foram a termoeletétrica de Pernambuco e distrito industrial de Maracanaú- CE e o entorno dos reservatórios de água de Sobradinho e Itaparica - BA e PE, respectivamente.

As áreas urbanas foram escolhidas devido a intensa circulação de automóveis, as áreas de atividades industriais devido à natureza dessas atividades já serem consideradas fontes potenciais de poluição e o entorno dos reservatórios para verificar os níveis de poluentes próximo a importantes fontes de água. Para a análise dos resultados, a delimitação das duas cidades foi feita de acordo com seus limites municipais. Para as áreas industriais e entorno de reservatórios de água foi considerado um buffer de $10 \mathrm{Km}$, a partir do centróide e de suas bordas, respectivamente.

Em todos os Estados da região Nordeste, a recomendação do distanciamento social teve início em meados de março de 2020. Além disso, algumas regiões adotaram períodos de restrição ainda mais intensas como foi o caso de Recife PE de 16 a 31 de maio de 2020 (PERNAMBUCO, 2020), São Luís - MA de 03 de abril a 20 de maio de 2020 (MARANHÃO, 2020) e Fortaleza- CE de 08 a 20 de maio de 2020 (FORTALEZA, 2020).

\section{MATERIAIS E MÉTODOS}

Para o desenvolvimento deste artigo foram utilizados os seguintes materiais e recursos tecnológicos: Imagens do satélite Terra/Aqua instrumento MODIS- AOD e Imagens do Sentinel - 5 Precursor instrumento TROPOMI - NRTI $\mathrm{NO}_{2}$, arquivos em formato shapefile fornecidos pelo Intituto Brasileiro de Geografia e Estatística (IBGE) e pela Agência Nacional de Águas e Saneamento Básico (ANA), Plataforma do Google Earth Engine, Dados de isolamento social disponibilizados pela empresa inloco e pelo Ministério Público de Pernambuco (MPPE), Software QuantumGIS versão 2.18.16, Software Excel 2016 e Notebook hp core i5 Sistema Operacional Windows 10

A metodologia aplicada no desenvolvimento desta pesquisa pode ser visualizada no fluxograma da Figura 2. 


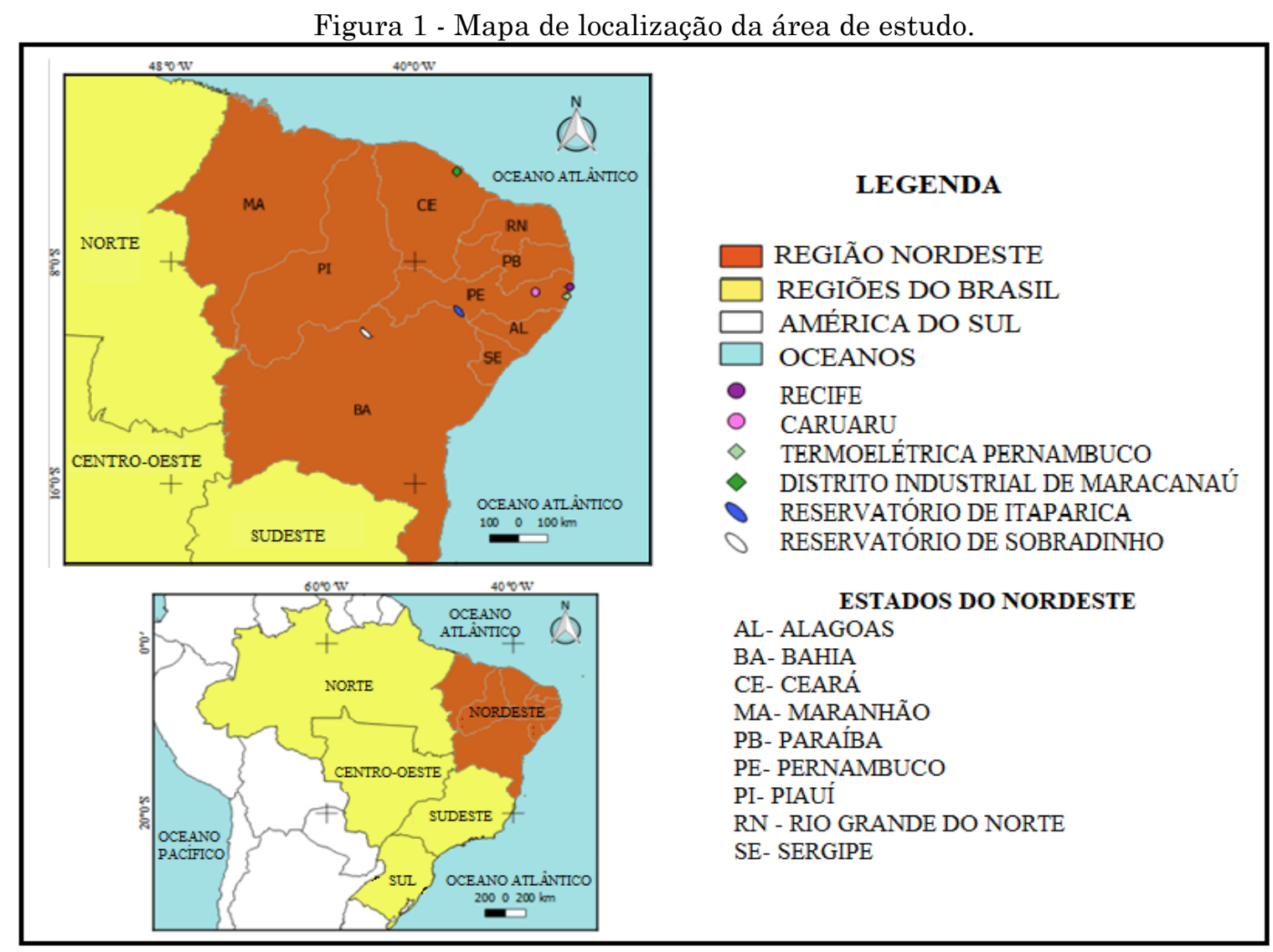

Fonte: Os autores.

Figura 2 - Fluxograma da metodologia

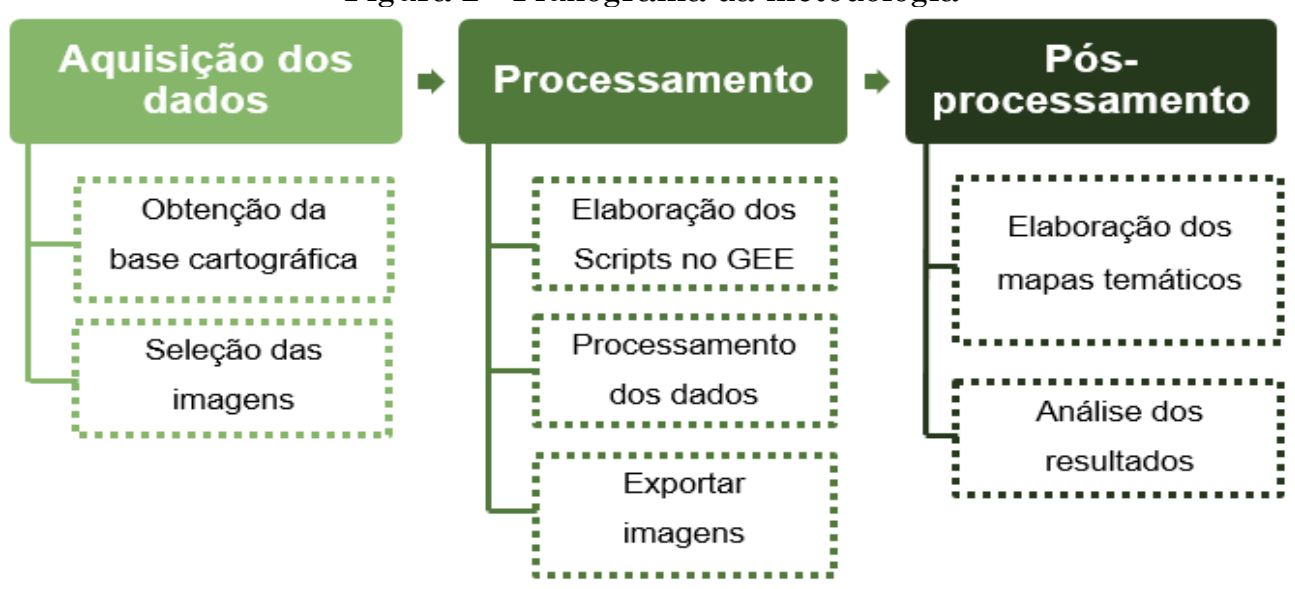

Fonte: Os autores.

Para a aquisição dos dados, inicialmente, na elaboração dos scripts no GEE foi delimitada a área de estudo. A base cartográfica em formato shapefile utilizada para este fim foi obtida no site do IBGE (2020) . Também foram obtidos arquivos shapefile para as áreas teste junto ao IBGE e a ANA (2020). Para os estudos relacionados ao $\mathrm{NO}_{2}$ foram utilizadas imagens do Sentinel- 5P TROPOMI, já para os estudos do AOD foram utilizadas imagens do terra e Aqua/MODIS. As imagens foram obtidas a partir de coleções disponibilizadas pelo GEE que detém produtos de parceiros e os disponibiliza gratuitamente para pesquisa, educação e uso sem fins lucrativos.

Em relaçao ao Processamento dos dados, na elaboração dos scripts em linguagem Java no GEE, também foi definido, através de filtros, o período de estudo que corresponde aos meses de janeiro a junho de 2019 e 2020 para o $\mathrm{NO}_{2}$ e AOD. Os produtos MODIS AOD possuem imagens históricas desde 2000 até o presente momento. Já o produto Sentinel $5 \mathrm{P} \mathrm{NO}_{2}$ disponibiliza dados a partir de julho de 2018, por isso, o ano de 2020 foi comparado apenas com 2019, a fim de verificar se no ano de 2020 houve mudanças significativas nos níveis de poluentes. Com o objetivo de 
compilar os dados a serem analisados nos resultados, as imagens foram agrupadas em bimestres, sendo o $1^{\circ}$ bimestre- janeiro e fevereiro, o $2^{\circ}$ bimestre- março e abril e o $3^{\circ}$ bimestre- maio e junho.

Além dos filtros para delimitar a área de estudo e período de estudo, também foi aplicado um filtro de média para calcular a variação do $\mathrm{NO}_{2}$ e AOD média por bimestre. Os dados de AOD são adimensionais, já os dados de $\mathrm{NO}_{2}$ são expressos em $\mu \mathrm{mol} / \mathrm{m}^{2}$, sendo o valor mínimo estimado $-600 \mu \mathrm{mol} / \mathrm{m}^{2}$ e o máximo 96001444.34 $\mu \mathrm{mol} / \mathrm{m}^{2}$.

As imagens obtidas dentro de cada coleção foram selecionadas observando-se a incidência de nuvens sobre a área de estudo durante o período de tempo analisado. Os dados MODIS e Sentinel possuem uma banda que indica a probabilidade de presença de nuvem em um determinado pixel variando de 0 (sem nuvens) a 1 (coberto com nuvens). Para evitar resultados enganosos, os pixels foram verificados e em todas as imagens a média de cobertura de nuvem apresentou valores até 0,4 .

Além disso, com o objetivo de garantir a qualidade das imagens, os dados vêm com uma banda de garantia de qualidade chamada 'qa_value' que indica a qualidade de um pixel numa escala de 0 (ruim) a 1 (bom), derivado de vários fatores, como: presença de nuvens, albedo de superfície, neve / gelo, saturação do sinal e geometria de aquisição. Antes de serem inseridos no GEE, os dados são filtrados visando remover pixels de baixa qualidade com 'qa_value' $<0,75$ (ALI et al., 2021).

Os dados foram processados em nuvem dentro da plataforma do GEE. Apesar da área de estudo ser bastante extensa, a capacidade computacional do GEE processou os dados em poucos minutos exibindo os resultados na tela. Esses resultados, foram então, exportados, também através de programação, para o Google Drive. Esta etapa foi necessária pois o GEE gera apenas resultados visuais não permitindo elaborar o layout dos mapas temáticos dentro da plataforma.

$\mathrm{Na}$ etapa de Pós- Processamento, após a obtenção dos resultados dentro da plataforma do GEE e de posse desses dados no Google Drive, as imagens foram baixadas e importadas no software QuantumGIS (QGIS) para fins de elaboração dos mapas temáticos.

Em seguida, as imagens foram classificadas e os mapas foram obtidos e optou-se por apresentar em um mesmo layout os dados para cada bimestre do ano de 2020 e 2019 para facilitar a comparação das alterações nos níveis de poluentes por meio de análises visuais. Baseado nas imagens bimestrais processadas, a variação temporal da concentração dos dois poluentes para cada estado foi mais explorada. A partir dos mapas temáticos, foram calculadas anomalias padronizadas para obter dados estatísticos das mudanças ocorridas de um ano em relação a outro. Esses dados forneceram uma ideia mais clara do quanto os níveis de poluentes divergiram entre os dois períodos de estudo. As anomalias foram calculadas utilizando-se a equação 1 .

$$
\text { anomalia }=\frac{x-\bar{x}}{\sigma \bar{x}}
$$

onde, $\mathrm{x}$ é o $\mathrm{NO}_{2} / \mathrm{AOD}$ médio bimestral para $2020 \mathrm{em} \mu \mathrm{mol} / \mathrm{m}^{2}$ para o $\mathrm{NO}_{2}$ e admensional para o AOD, e $\bar{x}$ é o $\mathrm{NO}_{2} / \mathrm{AOD}$ médio do ano de 2019 em bimestre e ox é o desvio padrão desses dados. Esses cálculos foram realizados por meio da calculadora raster do QGIS. Foram calculadas anomalias para cada estado do nordeste e para as áreas testes e os dados numéricos obtidos através das imagens foram utilizados no software excel para elaboração de gráficos de anomalias. Por fim, esses gráficos foram associados visualmente com índices de isolamento social em decorrência da Covid-19 disponibilizados pela empresa inloco e pelo Ministério Público de Pernambuco (MPPE, 2020).

\section{RESULTADOS E DISCUSSÃO}

Inicialmente serão apresentados os resultados para $\mathrm{NO}_{2}$, em que os mapas da Figura 3 apresentam a distribuição média deste poluente no território nordestino. Visualmente, pode-se identificar que a maioria dos estados, exceto Maranhão e Piauí no terceiro bimestre, têm uma maior média para 2019 do que 2020. Também, nota-se uma redução significativa nos níveis de $\mathrm{NO}_{2}$ em todos os estados durante o segundo bimestre do ano de 2020. O intervalo das classes foi definido analisando-se os valores mínimos e máximos de cada imagem e foi adotado o mesmo ponto de corte para que os dados pudessem ser comparados. O menor valor observado foi de 27 e o maior de 62 que representam a concentração do $\mathrm{NO}_{2}$ em $\mu \mathrm{mol} / \mathrm{m}^{2}$. 
Figura 3- Mapa das mudanças nos níveis $\mathrm{NO}_{2}$. (a), (b) e (c) primeiro, segundo e terceiro bimestre de 2019. (d), (e), (f), primeiro, segundo e terceiro bimestre de 2020

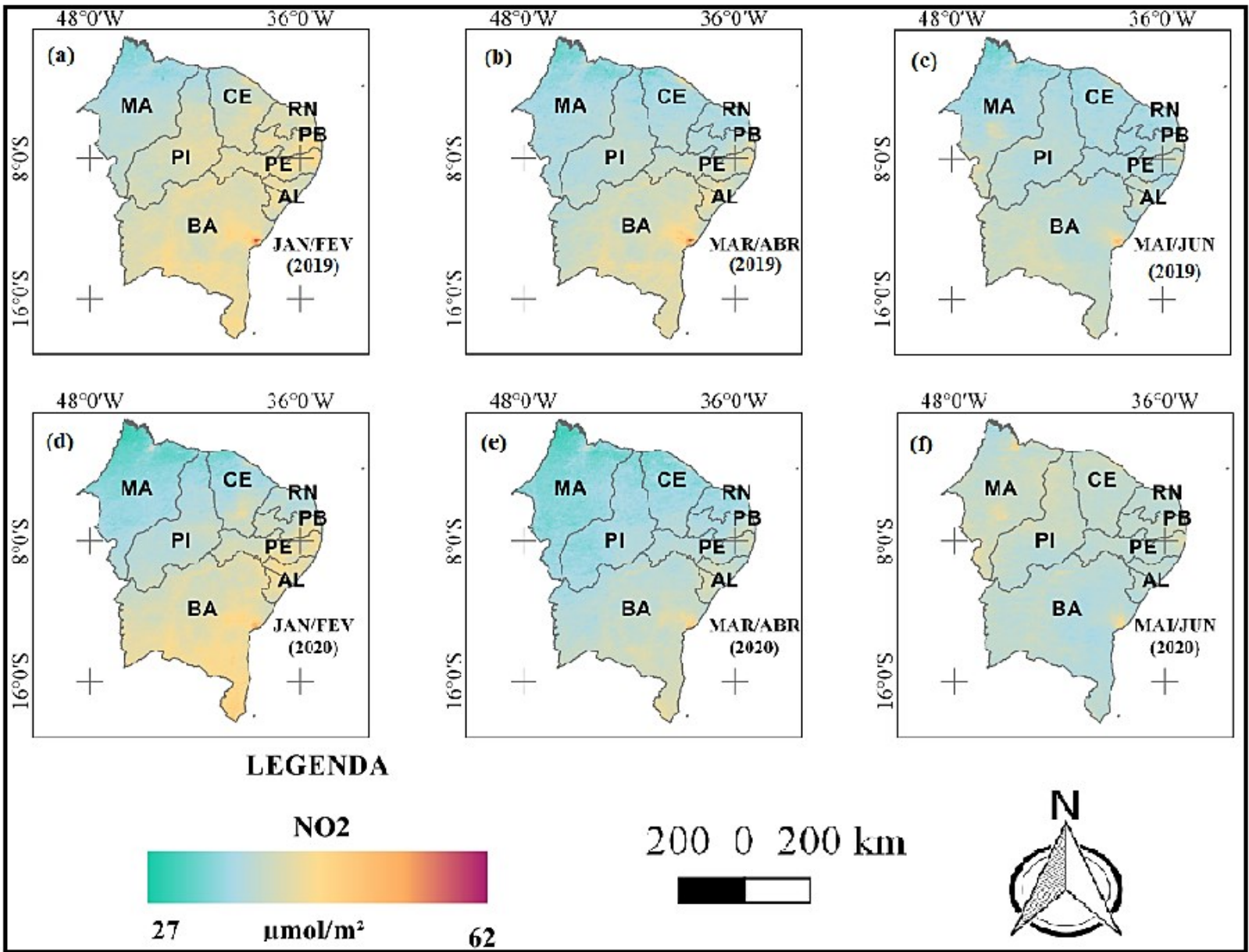

Fonte: Os autores.

Os resultados numéricos da imagem acima podem ser vistos na Tabela 1. Nela são apresentados a média da concentração de $\mathrm{NO}_{2}$ para os três bimestres de 2019 e 2020 bem como a variação em percentual. Verifica-se que a maior diminuição foi para o segundo bimestre $(-4,49 \%)$, já para o terceiro bimestre houve acréscimo de $2,26 \%$.

Tabela 1- Variação da media $\mathrm{NO}_{2}\left(\mu \mathrm{mol} / \mathrm{m}^{2}\right)$ por bimestre

\begin{tabular}{|c|c|c|c|}
\hline \multirow{2}{*}{ Bimestre } & \multicolumn{2}{|c|}{ ANO } & \multirow{2}{*}{$\begin{array}{c}\text { Variação em } \\
\text { porcentagem (\%) }\end{array}$} \\
\hline & 2019 & 2020 & \\
\hline $1^{\circ}$ bimestre & 40,263 & 38,870 & $-3,460$ \\
\hline $2^{\circ}$ bimestre & 38,321 & 36,601 & $-4,490$ \\
\hline $3^{\circ}$ bimestre & 37,541 & 38,391 & $+2,260$ \\
\hline
\end{tabular}

Fonte: Os autores.

Para uma melhor visualização das mudanças ocorridas no período de tempo analisado, a anomalia padronizada de $\mathrm{NO}_{2}$ de cada bimestre foi estimada através da Equação 1 e a partir delas, foi gerado um mapa da variação espacial média deste gás durante o ano de 2020 em comparação com a média do ano de 2019 (Figura
4).

Neste mapa, valores negativos (cor verde a amarela) apontam para um decréscimo no nível deste poluente enquanto que valores positivos (cor laranja a vinho) mostram um aumento do $\mathrm{NO}_{2}$. 
Figura 4- Anomalias $\mathrm{NO}_{2}$. (a), (b) e (c) primeiro, segundo e terceiro bimestre de 2020 com relação a 2019.

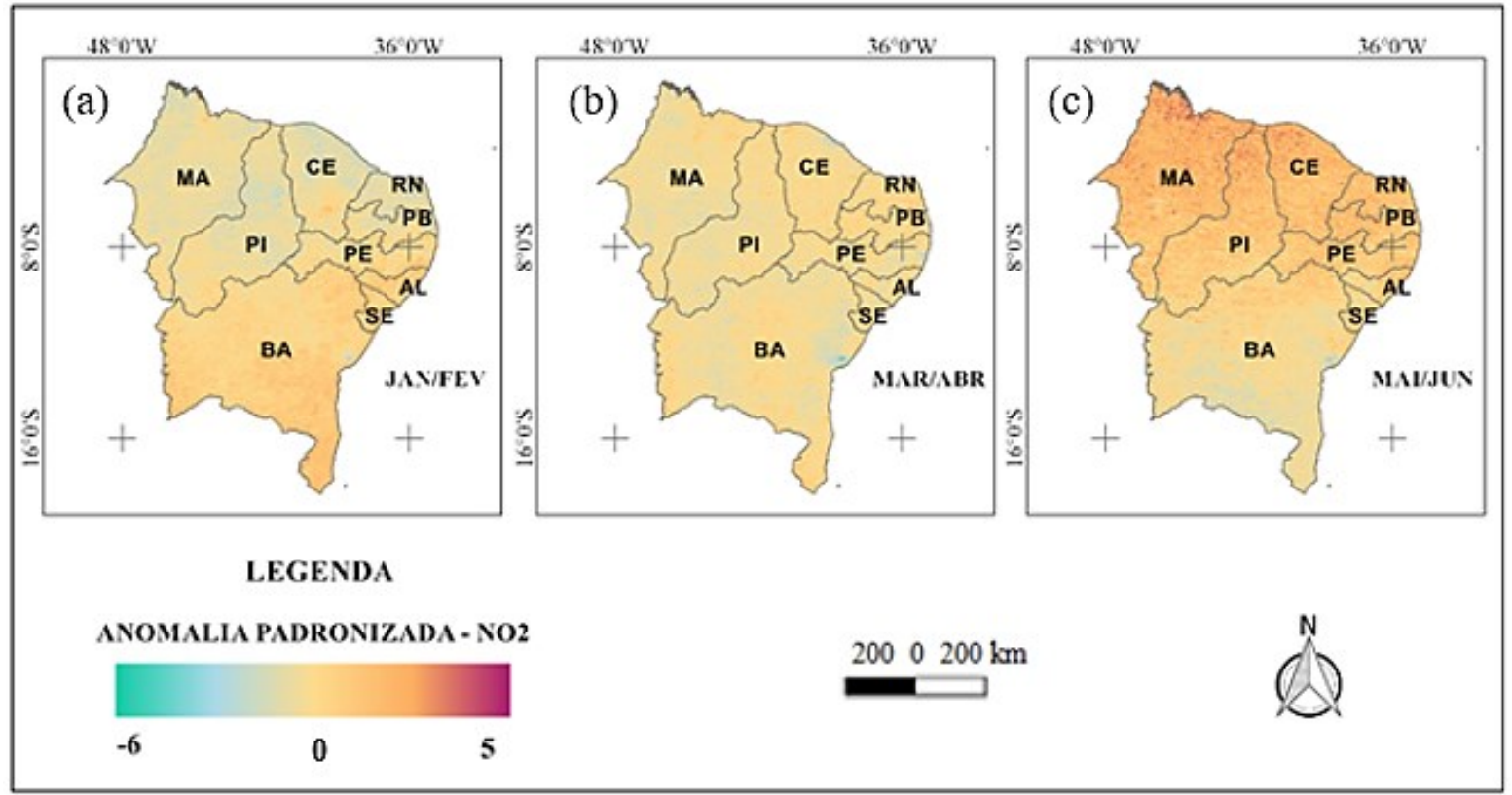

Fonte: Os autores.

A partir da Figura 4, nota-se no geral, uma redução significativa do $\mathrm{NO}_{2}$, principalmente no segundo bimestre, que corresponde aos meses de março e abril. Nota-se uma predominância na cor amarela indicando que os resultados de anomalias são negativos para a maior parte do território. Vale destacar, neste mesmo período, as regiões próximas as capitais da Bahia (BA) e Pernambuco (PE) apresentadas no mapa com a cor azul mostrando que os valores são ainda menores nessas regiões e que houve redução na concentração do poluente. No primeiro semestre também é perceptível que os valores de anomalias são negativos em grande parte do Nordeste, com destaque para a região da Bahia, que é uma exceção, e apresenta pixels classificados em uma cor mais próxima da laranja indicando anomalias positivas e pequenos aumentos na concentração desse gás. Já no terceiro bimestre é possível visualizar um aumento no $\mathrm{NO}_{2}$ em comparação com os bimestres anteriores devido à presença de pixels classificados na cor vermelho/vinho.

Para que esses resultados pudessem ser melhor analisados, foi realizada uma análise numérica das anomalias médias de $\mathrm{NO}_{2}$ por estado conforme apresentado na Figura 5. Através do gráfico de diagrama de barras, notase a anomalia máxima e mínima de $\mathrm{NO}_{2}$ de $+1,50$ e -1,25 para terceiro bimestre do estado no Maranhão (MA) e primeiro bimestre no estado do Rio Grande do Norte (RN), respectivamente. Todos os estados apresentaram anomalias negativas para o segundo bimestre e anomalias positivas no terceiro bimestre com exceção da Bahia e Sergipe (SE), que no terceiro bimestre apresentaram tendência de queda.

Ainda em relação à interpretação das anomalias geradas, foi feita uma classificação das concentrações de poluentes e, posteriormente, foram calculadas as áreas ocupadas por cada classe verificando-se o percentual que cada uma delas ocupava em relação a região Nordeste. Os Resultados podem ser vistos na Tabela 2 em que nota-se que a maior área para todos os bimestres corresponde as classes em torno de 0 indicando que não houveram alterações significativas entre os anos estudados na maior parte do território. 
Figura 5- Médias das anomalias $\mathrm{NO}_{2}$ por Estado.

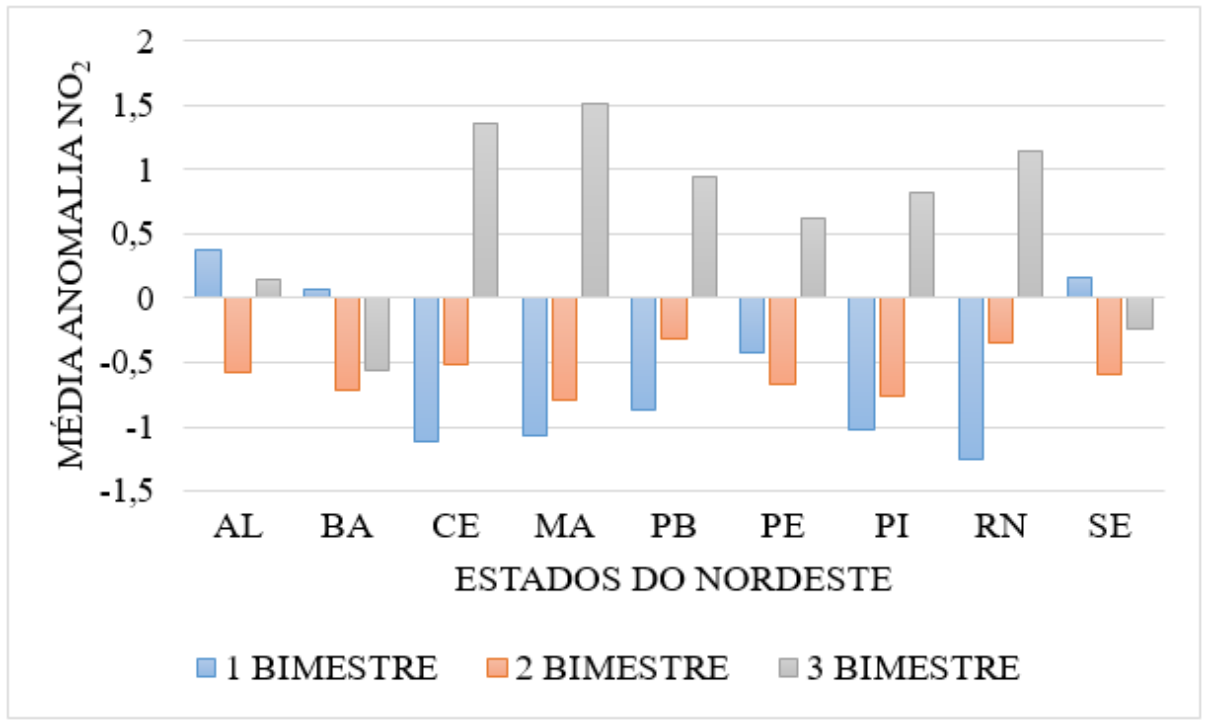

Fonte: Os autores.

Tabela 2- Área das anomalias $\mathrm{NO}_{2}$ por classe em $\mathrm{Km}^{2}$

\begin{tabular}{ccccccc}
\hline \multirow{2}{*}{ CLASSES } & \multicolumn{7}{c}{ ÁREA DAS ANOMALIAS NO $\mathbf{( \mathbf { K m } ^ { 2 } )}$} \\
& $\mathbf{1}^{\circ}$ BIMESTRE & ÁREA EM \% & $\mathbf{2}^{\circ}$ BIMESTRE & ÁREA EM \% & $\mathbf{3}^{\circ}$ BIMESTRE & ÁREA EM \% \\
\hline -6 a -4 & 0,000 & 0,000 & 36000,000 & 0,020 & 44040,000 & 0,030 \\
-4 a -2 & 2608000,000 & 1,650 & 1244000,000 & 0,790 & 1005000,000 & 0,640 \\
-2 a 0 & 116600000,000 & 73,800 & 54890000,000 & 34,750 & 143900000,000 & 91,140 \\
0 a 2 & 38770000,000 & 24,540 & 86190000,000 & 54,560 & 12990000,000 & 8,230 \\
2 a 5 & 23330,000 & 0,010 & 15640000,000 & 9,900 & 0,000 & 0,000 \\
\hline
\end{tabular}

\section{Fonte: Os autores.}

Esses resultados podem ser associados aos índices de isolamento social em decorrência da COVID-19 disponibilizados pela empresa inloco, pois, a emissão de poluentes está estritamente relacionada a atividades humanas. Diversos pesquisadores buscaram relacionar os efeitos do lockdown na poluição do ar em várias regiões do mundo (Berman e Ebisu, 2020; Ranjan et al., 2020). Na Tabela 3 são apresentados os índices de isolamento social por estado que mostram o percentual da população que respeitou a recomendação de permanecer em casa em cada bimestre analisado.

Tabela 3- Índices de isolamento social dos estados do Nordeste.

\begin{tabular}{cccc}
\hline ESTADOS & $\mathbf{1}^{\circ}$ bimestre & $\mathbf{2}^{\circ}$ bimestre & $\mathbf{3}^{\circ}$ bimestre \\
\hline ALAGOAS & $30,480 \%$ & $38,310 \%$ & $38,980 \%$ \\
BAHIA & $29,050 \%$ & $34,600 \%$ & $38,970 \%$ \\
CEARÁ & $29,470 \%$ & $34,850 \%$ & $38,840 \%$ \\
MARANHÃO & $29,220 \%$ & $34,730 \%$ & $38,810 \%$ \\
PARAÍBA & $29,220 \%$ & $34,640 \%$ & $39,750 \%$ \\
PERNAMBUCO & $30,130 \%$ & $39,190 \%$ & $40,160 \%$ \\
PIAUÍ & $30,050 \%$ & $39,100 \%$ & $40,120 \%$ \\
RIO GRANDE DO & $30,310 \%$ & $38,860 \%$ & $40,090 \%$ \\
NORTE & & $37,500 \%$ & $38,370 \%$ \\
SERGIPE & $28,520 \%$ & \\
\hline
\end{tabular}

Fonte: Os autores (2020). 
É possível notar, que em todos os Estados do Nordeste, os maiores índices de isolamento social apontam para o segundo e terceiro bimestre. De acordo com Baldasano (2020), este período corresponde ao período de rápido crescimento da pandemia em vários países acarretando na necessidade de isolamento da população como principal forma de diminuição do contágio da doença.

Com isso, em muitos municípios houve restrição da circulação de veículos e paralisação de diversas industrias e serviços, como: lojas, hotéis e restaurantes, permanecendo apenas atividades essenciais em várias localidades. Em algumas cidades houve até períodos de restrições ainda mais intensas como foi o caso de Recife PE (PERNAMBUCO, 2020), São Luís - MA (MARANHÃO,2020) e Fortaleza- CE (FORTALEZA, 2020).

Muitos pesquisadores apontaram que há evidências de que a mudança na concentração de poluentes está, pelo menos em parte, relacionada à desaceleração econômica após o surto do coronavírus (BALDASANO, 2020; BERMAN E EBISU, 2020; NASA, 2020). A partir do terceiro bimestre, muitas atividades começaram a ser retomadas, levando os índices de isolamento a diminuírem e consequentemente ao aumento da poluição. Esse crescimento pós isolamento também foi observado por pesquisadores em várias regiões do mundo principalmente na China, considerada epicentro da doença (NASA, 2020; REUTERS, 2020).

A Figura 6 apresenta a distribuição do AOD no território nordestino. $\mathrm{O}$ intervalo das classes foi definido analisando-se os valores mínimos e máximos de cada imagem e foi adotado o mesmo ponto de corte para que os dados pudessem ser comparados. $\mathrm{O}$ menor valor observado foi de 0 e o maior de 679 que representam a concentração do AOD. Visualmente, nota-se que a maioria dos estados nordestinos têm uma maior média para 2020 do que para 2019.

Figura 6- Mapa das mudanças nos níveis AOD. (a), (b) e (c) primeiro, segundo e terceiro bimestre 2019. (d), (e), (f), primeiro, segundo e terceiro bimestre de 2020.

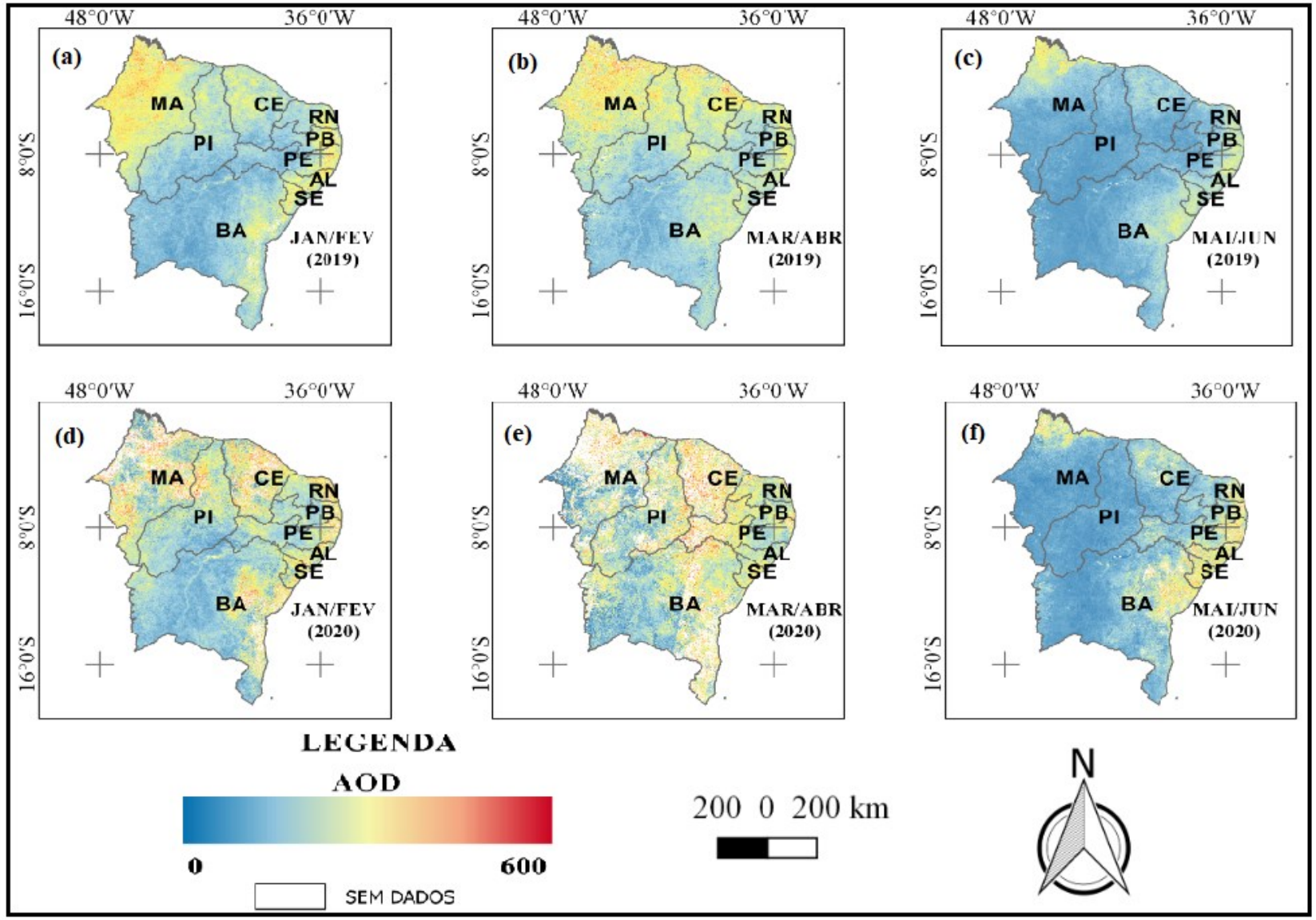

Fonte: Os autores. 
Os resultados numéricos da imagem acima podem ser vistos na Tabela 4. Nela são apresentados a média da concentração de AOD para os três bimestres de 2019 e 2020, bem como a variação em percentual. Verifica-se que a maior diminuição foi para o terceiro bimestre (-6,20\%) e a menor foi para o segundo bimestre em que houve acréscimo de 11,39\%.

Tabela 4- Variação media do AOD por bimestre.

\begin{tabular}{cccc}
\hline Bimestre & \multicolumn{2}{c}{ ANO } & $\begin{array}{c}\text { Variação em } \\
\text { porcentagem (\%) }\end{array}$ \\
\hline $1^{\circ}$ bimestre & 208,000 & 208,720 & $+0,350$ \\
$2^{\circ}$ bimestre & 219,840 & 244,890 & $+11,390$ \\
$3^{\circ}$ bimestre & 128,050 & 120,120 & $-6,200$ \\
\hline
\end{tabular}

Fonte: Os autores.

Para um melhor entendimento sobre a distribuição das mudanças nos níves de AOD no território nordestino, também foi estimada a anomalia padronizada de AOD de cada bimestre utilizando-se a Equação 1.

O mapa de anomalia do AOD pode ser visualizado na Figura 7, onde valores negativos (cor azul a amarela) apontam para um decréscimo no nível deste poluente enquanto que valores positivos (cor amarela a vermelha) mostram um aumento nos níveis de AOD.

Figura 7- Anomalias AOD. (a), (b) e (c) primeiro, segundo e terceiro bimestre de 2020 com relação

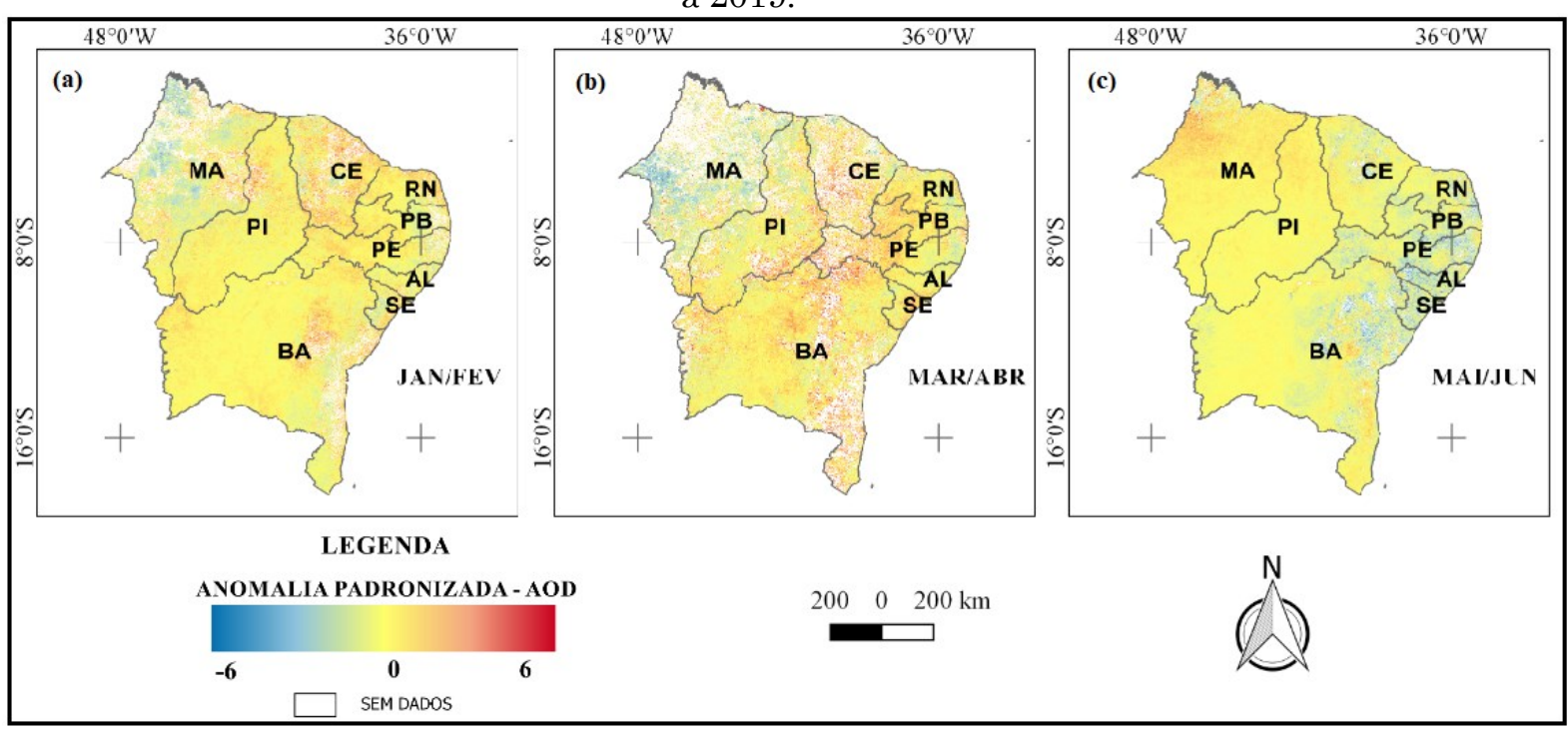

Fonte: Os autores.

Nota-se que na maior parte da área de estudo, não houveram mudanças significativas entre os anos de 2019 e 2020, apresentando anomalias em torno de zero (cor amarela). Porém, é possível visualizar mudanças nos níveis de AOD em algumas regiões específicas. Durante o terceiro bimestre, foi constatada anomalias negativas (Cor azul) principalmente na região do litoral. Enquanto que nos dois primeiros bimestres, notase a presença de anomalias positivas em alguns trechos na região central. Esses resultados foram constatados devido à presença das classes na cor vermelha indicando que as anomalias são positivas, em torno de 6 , e que houve aumento nos níveis de AOD.

Principalmente no segundo bimestre, existem algumas regiões com dados ausentes, representadas na cor branca. O MODIS AOD é recuperado usando o algoritmo de alvo escuro. A disponibilidade de dados em algumas regiões é afetada pela presença de superfícies brilhantes. De acordo com Levy et al.,(2010), a recuperação de AOD do MODIS torna-se desafiadora em regiões com alta reflectância de superfície, porém, 
esses dados são muito aceitos no meio acadêmico pois, existem diversos estudos de validação que comprovaram que cerca de $72 \%$ das recuperações de AOD estão dentro dos níveis de incerteza esperados (REMER et al., 2005; LEVY et al., 2010).

Para que esses resultados pudessem ser melhor analisados, foi realizada uma análise numérica das anomalias médias do AOD por estado conforme Figura 8. A partir do diagrama de barras, nota-se, a anomalia máxima e mínima de AOD de + 1,07 e -1,50 para segundo bimestre no estado do Ceará e terceiro bimestre no estado de Sergipe, respectivamente. Nota-se em quase todos os estados anomalias negativas para o terceiro bimestre com exceção ao Maranhão (MA) e Piauí (PI) e anomalias positivas em todos os estados para o primeiro e segundo bimestre com exceção do Maranhão.

Figura 8 - Médias das anomalias de AOD por Estado.

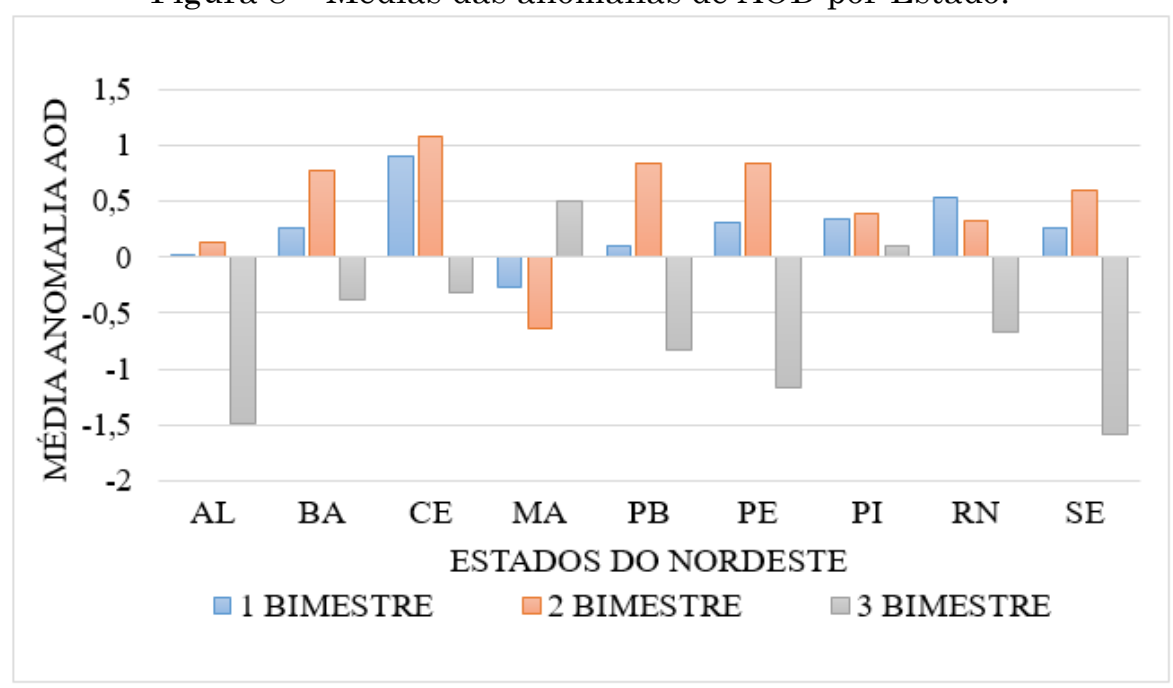

Fonte: Os autores.

Os resultados mostraram que apesar das possíveis desacelerações no convívio social, os índices de isolamento não foram suficientes para diminuir significativamente os níveis de AOD nos dois primeiros bimestres em relação ao ano de 2019. Autores como Ranjan et al., (2020) realizaram estudos semelhantes a esses buscando verificar os efeitos do bloqueio causado pela Covid-19 nos níveis de AOD em regiões urbanas e de mineração na Índia. Segundo esses autores, as razões para um nível mais alto de AOD mesmo com os efeitos dos períodos de bloqueio não são claras. Porém, esse aumento pode indicar a presença de recentes fontes poluidoras nesses locais em comparação com o período anterior. Além disso, os dados AOD de alguns pixels na região de estudo estavam ausentes e, portanto, isso pode fazer com que o nível de AOD apresente-se menor que os valores reais.

Sendo assim, os resultados podem ser justificados pela inconsistência no número de pixels AOD dentro dos limites administrativos do Nordeste durante os períodos correspondentes a 2019 e 2020. A contagem total de pixels AOD dentro dos limites administrativos dos estados não foi a mesma em todos os casos, portanto, pode existir uma ligeira variação na anomalia AOD em todo o território nordestino. Baldasano (2020), também diz que outro fator essencial é que durante o bloqueio parcial, os caminhões continuaram circulando, pois foram mantidas as atividades industriais e de construção, bem como, o transporte de alimentos e cargas em geral. Outra hipótese discutida por diversos autores é que os aerossóis não são apenas emitidos para a atmosfera por fontes antropogênicas, mas também, são gerados através de diversos processos físicos e químicos (SEINFELD; PANDIS, 2006).

Ainda em relação à interpretação das anomalias geradas, também foi feita uma classificação das concentrações de AOD e, posteriormente, foram calculadas as áreas ocupadas por cada classe verificando-se o percentual que cada uma delas ocupava em relação a região Nordeste. Os Resultados podem ser vistos na Tabela 5 onde nota-se que a maior área em todos os bimestres corresponde a classes em torno de 0 indicando que não houveram alterações significativas entre os anos estudados. Vale destacar que no primeiro e segundo bimestre, principalmente, o somatório das áreas de cada classe apresentou-se menor que o valor real devido a ausência de dados AOD em alguns trechos das imagens. 
Tabela 5- Área das anomalias AOD por classe em $\mathrm{Km}^{2}$

\begin{tabular}{ccccccc}
\hline \multirow{2}{*}{ CLASSES } & \multicolumn{5}{c}{ ÁREA DAS ANOMALIAS AOD $\left(\mathbf{K m}^{2}\right)$} \\
\cline { 2 - 7 } & $\mathbf{1}^{\circ}$ BIMESTRE & ÁREA EM \% & $\mathbf{2}^{\circ}$ BIMESTRE & ÁREA EM \% & $\mathbf{3}^{\circ}$ BIMESTRE & ÁREA EM \% \\
\hline <-6 a -3 & 2293000,000 & 1,620 & 2608000,000 & 2,070 & 112300,000 & 0,070 \\
-3 a 0 & 62010000,000 & 43,920 & 38240000,000 & 30,370 & 75740000,000 & 50,020 \\
0 a 3 & 71500000,000 & 50,640 & 66530000,000 & 52,830 & 71400000,000 & 47,150 \\
3 a 5 & 5333000,000 & 3,780 & 11870000,000 & 9,430 & 3870000,000 & 2,560 \\
5 a $\geq 6$ & 65760,000 & 0,050 & 6675000,000 & 5,300 & 307300,000 & 0,200 \\
\hline
\end{tabular}

Fonte: Os autores.

Também buscou-se verificar as alterações dos poluentes $\mathrm{NO}_{2}$ e AOD em algumas áreas estratégicas. Os dados de média das anomalias foram recortados para essas áreas. Esse recorte foi realizado para permitir uma análise mais detalhada das variações de poluentes (Figura 9).

Figura 9 - Médias das anomalias de $\mathrm{NO}_{2}$ (a) e AOD (b) por áreas testes.

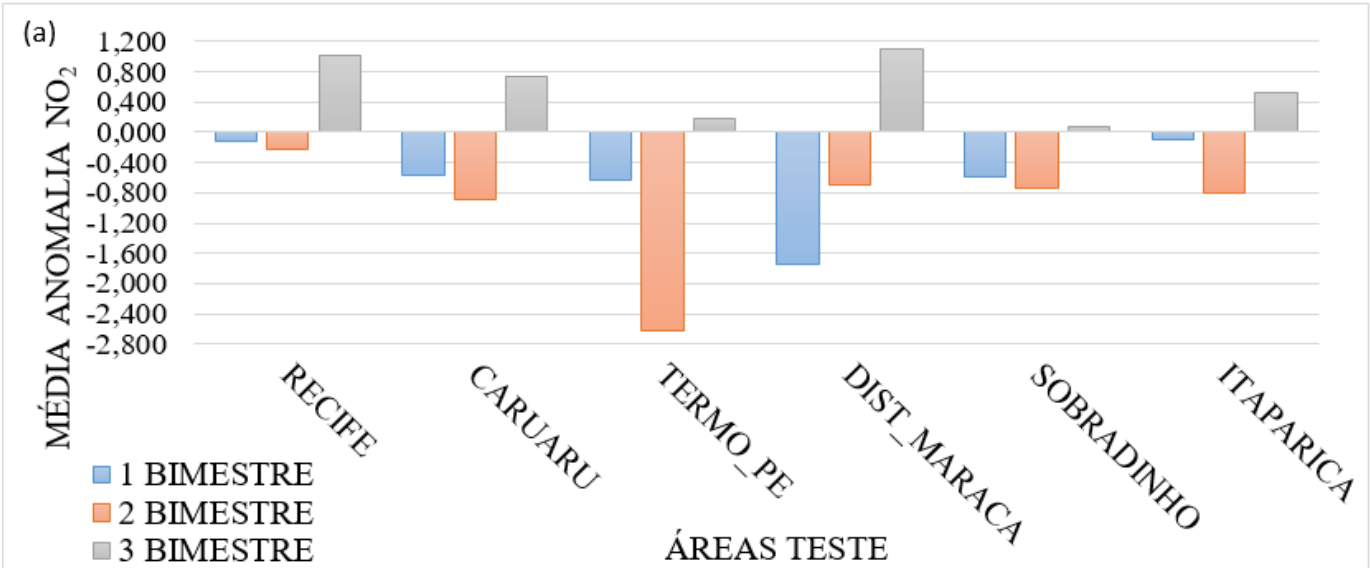

(b)

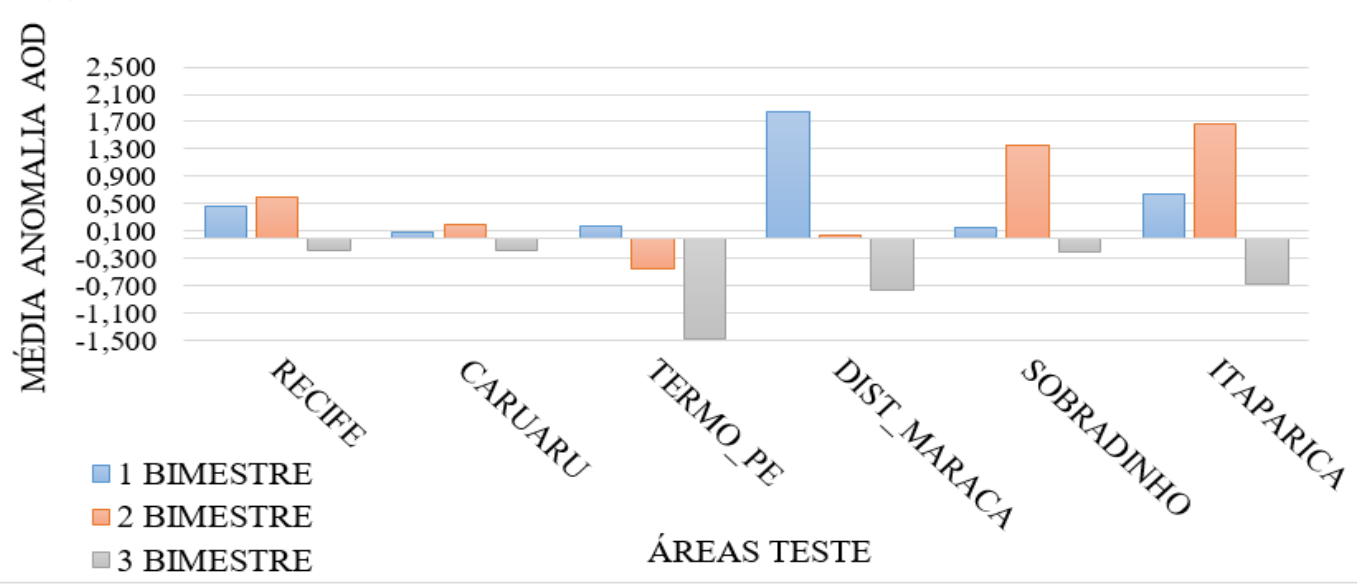

Fonte: Os autores.

É importante destacar que além do isolamento social, outros fatores também afetam a dispersão de poluentes na atmosfera, como é o caso da precipitação. Sendo assim, diferentes regimes de chuvas podem ter ocasionado mudanças entre as concentrações de poluentes em 2019 e 2020 (DANTAS et al., 2020). Tambem ressalta-se que o tempo de permanência do AOD na atmosfera é mais longo do que o $\mathrm{NO}_{2}$, podendo os aerossóis ser transportadas para regiões distantes ao contrário do $\mathrm{NO}_{2}$, que concentra-se próximo ao local de sua emissão (FILONCHYK et al., 2020).

Os resultados obtidos mostram que há coerência entre a análise realizada para a região como um todo e para as áreas testes, pois para o $\mathrm{NO}_{2}$ nota-se diminuição nos dois primeiros 
bimestres e no AOD essa diminuição só ocorre no terceiro bimestre (Figuras 4 e 8).

A partir da análise da Figura 9a, percebe-se que o primeiro e o segundo bimestre apresentam anomalias negativas em todas as áreas testes. Já o terceiro bimestre apresenta anomalias positivas em todas as áreas com destaque para as regiões da termoelétrica de Pernambuco e Sobradinho em que as anomalias também foram positivas, porém menores do que as demais áreas.

Já os resultados ds Figura 9b mostram que as anomalias foram positivas para praticamente todas as áreas no primeiro e segundo bimestre com exceção ao segundo bimestre da termoelétrica de Suape que foi negativo. Já o terceiro bimestre apresentou anomalias negativas em todas as áreas.

Analisando-se as cidades de Recife e Caruaru, a diminuição observada nos dois primeiros bimestres para o poluente $\mathrm{NO}_{2}$ pode ser justificada pelos índices de isolamento, em que os maiores índices, concentraram-se nos meses de março a meados de maio para ambas as cidades. Isso se deve ao fato de que as emissões de $\mathrm{NO}_{2}$ estão estritamente relacionadas a ações antropicas (CLARK et al., 2018; ALBERS, 1994).

Outro fator importante que pode ter contribuído para redução dos níveis de $\mathrm{NO}_{2}$ é que em meados do mês de março, o governo de Pernambuco emitiu um decreto (PERNAMBUCO, 2020), considerando a recomendação das autoridades sanitárias do País e do Estado buscando diminuir o fluxo de pessoas em espaços coletivos, para mitigar a disseminação do coronavírus em Pernambuco.

Após essa restrição mais rigorosa, foi iniciada medidas de retomada econômica e os índices de isolamento começaram a diminuir e consequentemente os níveis de $\mathrm{NO}_{2}$ voltaram a subir. Essa diminuição seguida por um aumento nos níveis de poluentes também foi observada por pesquisadores da NASA (2020) na região da China.

Em relação as áreas industriais, o comportamento nos níveis de $\mathrm{NO}_{2}$ foi igual aos das demais áreas. Apesar de não haver paralisação total das atividades industriais durante a pandemia, pode ter ocorrido uma redução parcial em seu funcionamento devido à diminuição no número de funcionários e dificuldade para compra de insumos.

Os resultados detalhados para as duas cidades e áreas industriais em relação ao AOD foram semelhantes e podem ser justificados pelos mesmos motivos que na análise realizada por estado em que os índices de isolamento não foram suficientes para diminuir significativamente os níveis de AOD nos dois primeiros bimestres em relação ao ano de 2019 .
No Brasil, Dantas et al., (2020) avaliaram os impactos do bloqueio social na cidade do Rio de Janeiro em relação ao monóximo de carbono (CO), $\mathrm{NO}_{2}$, materiais particulados e ozônio $\left(\mathrm{O}_{3}\right)$. Os resultados mostraram que o confinamento parcial da população, a redução do tráfego rodoviário e da atividade econômica levaram à diminuição em pequenos níveís de $\mathrm{NO}_{2}$. Isso porque os veículos pesados (caminhões e ônibus), movidos a diesel, contribuem com 91 e $96 \%$ dos óxidos de nitrogênio e durante o bloqueio parcial, os caminhões continuaram circulando, já que foram mantidas as atividades industriais e de construção, bem como, o transporte de alimentos e cargas em geral. Já os aerossóis reduziram apenas durante a primeira semana de bloqueio parcial.

Brandão (2020) analisou mudanças na qualidade do ar em São Paulo (SP) e Rio de Janeiro (RJ) através da combinação de dados de satélite e terrestre. Dados diários de $\mathrm{NO}_{2}$ e aerossóis foram explorados para o mês de maio entre 2015-2020. Foram encontrados decréscimos médios de $45 \%$ para 2020 em comparação com a média de 2015-2019. Para os aerossóis, nenhuma mudança significativa foi observada para 0 mesmo período de tempo, porém, destacou-se o elevado número de queimadas na região Sudeste que pode ter afetado os resultados.

Para Filonchyk et al., (2020) que estudaram $\mathrm{NO}_{2}, \mathrm{CO}$ e AOD antes e durante a pandemia no leste da China, o bloqueio da COVID-19 melhorou a qualidade do ar no curto prazo, mas assim que o consumo de carvão nas usinas e as refinarias voltaram aos níveis normais devido à retomada das atividades. $\mathrm{O} \quad \mathrm{CO}$ e $\mathrm{NO}_{2}$ apresentaram diminuição significativa (20 e 30\%, respectivamente) já o AOD apresentou altos valores e isso pode ter ocorrido devido ao tempo de permanência muito mais longo das partículas de aerossol na atmosfera, em contraste com algumas horas para $\mathrm{NO}_{2}$, eles podem ser transportadas para longas distâncias de onde foram gerados ao contrário do $\mathrm{NO}_{2}$ que fica concentrado próximo a suas fontes poluidoras.

Em relação ao entorno dos reservatórios de água tanto para tanto para o $\mathrm{NO}_{2}$ quanto para o AOD, Silva et al., (2011) afirmam que devido ao grande porte dos reservatórios, o monitoramento torna-se uma tarefa de difícil execução para os órgãos gestores, mas que ações antrópicas podem auxiliar em processos como o da eutrofização e acidificação das águas. $\mathrm{O} \mathrm{NO}_{2}$, por exemplo, reage com a água presente no ar formando o ácido nítrico $\left(\mathrm{HNO}_{3}\right)$ que é um dos principais componentes da chuva ácida que provoca a acidificação dos ambientes aquáticos (CHIUFFA, 2018). Sendo assim, ambientes aquáticos podem sofrer com a presença de contaminantes químicos provenientes de aerossóis e demais poluentes 
atmosféricos. Os resultados obtidos mostraram que os níveis de poluentes nessas regiões apresentaram comportamentos semelhantes aos das áreas urbanas e industriais, fato este que merece destaque e mostra a necessidade de monitoramento de poluentes nestas áreas.

\section{CONCLUSÕES}

A presente pesquisa mostrou que o nível de $\mathrm{NO}_{2}$ em quase todo o Território Nordestino foi reduzido no segundo bimestre de 2020 , com queda de $4,49 \%$, que corresponde ao período de rápido crescimento da pandemia e início dos eventos de bloqueio social desencadeados pela Covid-19. Já o terceiro bimestre, marcado pela retomada econômica, apresentou aumento de 2,26\%.

Em relação ao AOD, os resultados apontaram que apesar das desacelerações no convívio social, não houve diminuição significativa dos níveis de AOD nos dois primeiros bimestres de 2020 em relação ao ano de 2019 , cada um deles com aumento de $0,35 \%$ e $11,39 \%$ respectivamente, e uma das possíveis justificativas para esse fato é que os dados AOD de alguns pixels na região de estudo estavam ausentes e, portanto, isso pode ter feito o nível de AOD apresentar-se menor que os valores reais. Esta é uma das limitações da análise apresentada neste trabalho, a não extração de valores de alguns pixels AOD para alguns locais. Neste sentido, os resultados poderiam variar ligeiramente se todos os valores de pixel fossem considerados, porém, ainda assim, com base nos nossos resultados e de demais pesquisadores, acredita-se que as principais conclusões deste estudo permanecem válidas. Para o terceiro bimestre foi observada uma redução de 6,19\% no nível do AOD.

A verificação dos níveis de poluentes nas áreas estratégicas adotadas nesta pesquisa revelou que existe uma semelhança entre a análise para a região nordeste como um todo e para as áreas testes, pois para o $\mathrm{NO}_{2}$ notou-se diminuição nos dois primeiros bimestres e no AOD essa diminuição só ocorreu no terceiro bimestre. Assim, a partir das análises realizadas, concluise que as imagens de satélite podem ser uma boa alternativa para o monitoramento da qualidade do ar em relação a estações de monitoramento terrestre ja que estas apresentam um monitoramento limitado pelo alto custo e baixa cobertura espacial. Além disso, esse monitoramento é fundamental para entender os impactos que as atividades antropogicas têm na emissão de poluentes do ar.

\section{REFERÊNCIAS}

ALBERS, W. M. Indoor air pollution: NO, NO2, $\mathrm{CO}$, and $\mathrm{CO} 2$. The journal of allergy and clinical immunology, v. 94, n. 2, p. 289-295, 1994. https://doi.org/10.1016/00916749(94)90088-4.

ALI, G. et al. 2021. Environmental impacts of shifts in energy, emissions, and urban heatisland during the COVID-19 lockdown across Pakistan. Journal of Cleaner Production, v. 291, p. 125806, 2021. https://doi.org/10.1016/j.jclepro.2021.125806.

ANA - AGÊNCIA NACIONAL DE ÁGUAS E SANEAMENTO BÁSICO, 2020.ANA metadatacatalog. Disponível em: https://metadados.snirh.gov.br/geonetwork/srv/po r/catalog.search\#/home. Acesso em: 07/10/2020.

BALDASANO, J. M. COVID-19 lockdown effects on air quality by NO2 in the cities of Barcelona and Madrid (Spain). Science of The Total Environment, v.741, n.1 p. 140353, 2020. https://doi.org/10.1016/j.scitotenv.2020.140353.

BRANDÃO, R. Atmospheric Pollutant Levels in Southeast Brazil During COVID-19 Lockdown: Combined Satellite and Ground-based Data Analysis. 2020. Dissertação (Mestrado Engenharia Ambiental) - Faculdade da Virginia, Polytechnic Institute and State University, Virgínia, 2020. Disponível em:

https://vtechworks.lib.vt.edu/handle/10919/10202 6. Acesso em 06/05/2020.

BECHLE, M. J.; et al. Remote sensing of exposure to NO2: satellite versus ground-based measurement in a large urban area. Atmos. Environ., v. 69, p. 345-353, 2013. https://doi.org/10.1016/j.atmosenv.2012.11.046 .

BERMAN, J. D.; EBISU, K. Changes in U.S. air pollution during the COVID-19 pandemic. Science of the total environment, v. 739, p. 139864,

2020. https://doi.org/10.1016/j.scitotenv.2020.139864. CHUDNOVSKY, A.; LYAPUSTIN, A.; WANG, Y.; TANG, C.; SCHWARTZ, J.; KOUTRAKIS, P. High resolution aerosol data from MODIS satellite for urban air quality studies. Central European Journal of Geosciences, v. 6, n. 1, p. 17-26, 2014. https://doi.org/10.2478/s13533012-0145-4.

CLARK, L. P.; MILLTE, D. B.; MARSHALL, J. D. National Patterns in Environmental Injustice and Inequality: Outdoor NO2 Air Pollution in the United States. PLoS ONE, v. 9, n. $4, \quad$ p. $94431, \quad 2018$. https://doi.org/10.1371/journal.pone.0094431. CHIUFFA, V. P. D. Analysis of the emission 
and deposition of air pollutants that affect aquatic environments through the operation of a distribution center. 2018. Dissertação (Mestrado em Engenharia civil) Faculdade de Engenharia do Cmapus Ilha Solteira - UNESP, Universidade Estadual Paulista "Júlio De Mesquita Filho", Ilha Solteira, 2018. Disponível em: https://repositorio.unesp.br/bitstream/handle/114 49/180145/2-s2.0-

85052680129.pdf? sequence $=1 \&$ is Allowed $=\mathrm{y}$.

DANTAS, G. et al. The impact of COVID-19 partial lockdown on the air quality of the city of Rio de Janeiro, Brazil. Science of the Total Environment, v. 729, 139085 p., 2020. https://doi.org/10.1016/j.scitotenv.2020.139085.

ESA - Agência Espacial Europeia, 2020. Sentinel - 5P. Disponível em: https://sentinel.esa.int/web/sentinel/missios/senti nel-5p. Acesso em: 10/11/2020.

FILONCHYK, M.; et al. Impact Assessment of COVID-19 on Variations of SO2, NO2, CO and AOD over East China. Aerosol and air quality research, v. 20, n. 7, p. 1530-1540, 2020. https://doi.org/10.4209/aaqr.2020.05.0226.

FORTALEZA. Decreto No. 14663 de 05/05/2020. Estabelece, na cidade de Fortaleza, a Política de Rígido Isolamento Social como medida de enfrentamento à COVID - 19, e dá outras providências. Disponível em: https://www.legisweb.com.br/legislacao/?id=394 831. Acesso em: 02/11/2020.

GEE- GOOGLE EARTH ENGINE. Disponível em: https://earthengine.google.com/. Acesso em: 06/11/2020.

GEE- GOOGLE EARTH ENGINE, 2020. Sentinel-5P NRTI NO2: Near Real-Time Nitrogen Dioxide. Disponível em: https://developers.google.com/earth-

engine/datasets/catalog/COPERNICUS_S5P_NR

TI L3 NO2. Acesso em: 09/11/2020.

HOU, Y.; WANG, L.; ZHOU, Y.; WANG, S.; LIU, W.; ZHU, J. Analysis of the tropospheric column nitrogen dioxide over China based on satellite observations during 2008-2017. Atmospheric Pollution Research, v. 10, n. 2, p. 651-655, 2019. https://doi.org/10.1016/j.apr.2018.11.003.

IBGE - Instituto Brasileiro de Geografia e Estatística, 2020. Territorial divisions. Disponível em: https://www.ibge.gov.br/geociencias/organizacao -do-territorio/malhas-territoriais.html. Acesso em: 12/11/2020.

IBGE - Instituto Brasileiro de Geografia e Estatística, 2016. agricultural census. Disponível em: https://biblioteca.ibge.gov.br/visualizacao/livros/1 iv61914.pdf. Acesso em: 12/11/2020.
IEMA- Instituto de Energia e Meio Ambiente, 2018. National Air Quality Platform. Disponível em: http://energiaeambiente.org.br/. Acesso em: 11/10/2020.

INLOCO- Covid-19 Brazilian Map, 2020. Disponível em: https://mapabrasileirodacovid.inloco.com.br/pt/. Acesso em: 11/10/2020.

KAPLAN, G., ADVAN, Z. Y. Space-borne air pollution observation from sentinel-5p tropomi: relationship between pollutants, geographical and demographic data. International Journal of Engineering and Geosciences (IJEG), v. 5, n. 3, p. 130-137, 2020. https://doi.org/10.26833/ijeg.644089.

LAL, P. et al. The dark cloud with a silver lining: Assessing the impact of the SARS COVID-19 pandemic on the global environment. Science of the total environment, v. 732 , p. 139297 , 2020.

https://doi.org/10.1016/j.scitotenv.2020.139297.

LEVY, R.C. et al. Global evaluation of the collection 5 MODIS dark-target aerosol products over land. Atmospheric Chemistry and Physics, v. 10, p. 10399-10420, 2010. https://doi.org/10.5194/acp-10-10399-2010.

MARANHÃO. Decreto No. 35784 de 03/05/2020.

Estabelece as medidas preventivas e restritivas a serem aplicadas na Ilha do Maranhão (São Luís, São José de Ribamar, Paço do Lumiar e Raposa), conforme COVID-19. Disponível em: https://www.legisweb.com.br/legislacao/?id=394 644. Acesso em: 02/11/2020.

MPPE- Ministério Público de Pernambuco. Social isolation ranking. Disponível em: https://datastudio.google.com/u/0/reporting/1CaZ 15DfH_Ohj1wmb7mArBDpdZkna1r9q/page/LSr OB? $=$ =p3vHxnrBoWE. Acesso em: 21/11/2020.

MOURA, R. S. T.; LOPES, Y. V. A.; SILVA, G. G. $H$. Sedimentation of nutrients and particulate matter in a reservoir under the influence of fish farming activities in the semi-arid region of Rio Grande do Norte. New Chemistry, v.37, n. 8, p. 1283-1288, 2014. Disponível em: http://static.sites.sbq.org.br/quimicanova.sbq.org. br/pdf/v37n8a04.pdf. Acesso em: 13/11/2020.

NASA - Administração Nacional do Espaço e da Aeronáutica, 2020. Airborne Nitrogen Dioxide Plummets Over China. Disponível em:

https://earthobservatory.nasa.gov/images/146362/ airborne-nitrogen-dioxide-plummets-over-china.

Acesso em: 13/11/2020.

NASA - Administração Nacional do Espaço e da Aeronáutica, 2020. Nitrogen Dioxide Levels Rebound in China. Disponível em: https://earthobservatory.nasa.gov/images/146741/ nitrogen-dioxide-levels-rebound-in-china. Acesso 
em: 13/11/2020.

OMS - Organização Mundial de Saúde, 2020. Joint Mission Report Who-China on Coronavirus Disease 2019 (Covid-19). Disponível em: https:/cutt.ly/on20Fbb. Acesso em: 13/11/2020.

OMS - Organização Mundial de Saúde, 2016. Ambient air pollution: A global assessment of exposure and burden of disease. Disponível em: https://www.who.intıphes publications>air-pollution-global-assessment. Acesso em: 13/11/2020.

PERNAMBUCO. Decreto No. 48832 de 19/03/2020. Definir, no âmbito socioeconômico, medidas restritivas temporárias adicionais para fazer frente à emergência de saúde pública de importância internacional decorrente do Coronavírus. Disponível em: https://www.legisweb.com.br/legislacao/?id=390 952. Acesso em: 02/11/2020.

PERNAMBUCO. Decreto No. 49017 de 11/05/2020. Dispõe sobre a intensificação de medidas restritivas, de caráter excepcional e temporário, destinadas a conter a curva de disseminação da Covid-19. Disponível em: https://www.legisweb.com.br/legislacao/?id=395 175. Acesso em: 02/11/2020.

PRADO, N. V.; COELHO, S. M. S. C. 2017. Study of the Temporal Variability of the Optical Depth of the Aerosol Using Remote Sensing Data on the Transition Region between the Amazon Forest and the Cerrado. Brazilian magazine of meteorology, v. 32, n. 4, 2017. https://doi.org/10.1590/0102-7786324012 .

RANJAN, A. K.; PATRA, A. K.; GORAI, A. K. Effect of lockdown due to SARS COVID-19 on aerosol optical depth (AOD) over urban and mining regions in India. Science of The Total Environment, v. 745, n. 25,p. 141024, 2020. https://doi.org/10.1016/j.scitotenv.2020.141024.

REMER L.A.et al. The MODIS aerosol algorithm, products, and validation. Journal of the Atmospheric Sciences, v. 62, p. 947-973, 2005. https://doi.org/10.1175/JAS3385.1.

REUTERS, A. S. China see post-lockdowns rise in air pollution: study. Disponível em:
https:/cutt.ly/Nn201. Acesso em: 14/09/2020.

RIVERA, E. A. C. Systemic Model to Understand the Eutrophication Process in a Water Reservoir. 2003. Dissertação (Mestrado in Engenharia de alimentos) Faculdade de Engenharia de Alimentos, Universidade Estadual de Campinas, 2003. Disponível em: https://pdfs.semanticscholar.org/13cd/883 cf96e0 de76fa8f21bdecf52798cc0aa5c.pdf. Acesso em: 11/09/2020.

SEINFELD J.H., PANDIS S.N. Atmospheric Chemistry and Physics From: Air Pollution to Climate Change (2nd), John Wiley and Sons (2006). Disponível em: https://bit.ly/3d2AB50. Acesso em: 09/09/2020.

SILVA, M. P. et al. Identification of areas of potential eutrophication in the lake of sobradinho-ba using remote sensing. In : $26^{\circ}$ Congresso Brasileiro de Engenhaia Sanitária e Ambiental, 2011. Disponível em: http://abes.locaweb.com.br/XP/XP-

EasyArtigos/Site/Uploads/Evento19/Trabalhos CompletosPDF/IV-239.pdf. Acesso em: 03/09/2020.

SOUZA, A.; SANTOS, D. A. S.; CLADIN, L. P. G. Urban air pollution from MODIS aerosol data: effect of meteorological parameters. Bol. Goia. Geogr., v. 37, n. 3, p. 466-483, 2017. Disponível em:

https://www.redalyc.org/pdf/3371/33715429600 6.pdf Acesso em: 22/10/2020.

UN - United Nations, 2019. Revision of World Population Prospect. Disponível em: < https://population.un.org/wpp/>. Acesso em: 18/10/2020

\section{CONTRIBUIÇÃO DOS AUTORES}

Laízy de Santana Azevedo conceituou, fez a metodologia, analisou e redigiu. Ana Lúcia Bezerra Candeias e João Rodrigues Tavares Junior supervisaram e redigiram. 